\title{
Geração, tratamento e disposição final dos resíduos das estações de tratamento de água do estado de Pernambuco
}

\author{
Generation, treatment and final disposal of the waste of \\ water treatment stations in the state of Pernambuco, Brazil \\ Maurício Alves da Motta Sobrinho'* (i), Rosângela Gomes Tavares' ${ }^{\circledR}$, \\ Valmir Cristiano Marques de Arruda' ${ }^{\mathbb{D}}$, Marcus Metri Correa' ${ }^{\circledR}$, Luciana José Ribeiro Pereira² ${ }^{\mathbb{C}}$
}

口-

\begin{abstract}
RESUMO
Este artigo aborda a geração, a quantificação e a disposição final de lodos gerados nas estações de tratamento de água (ETAs) existentes e em operação no estado de Pernambuco. A pesquisa foi realizada no período de janeiro de 2015 a dezembro de 2016, a partir da coleta, sistematização e interpretação de dados que mostraram a existência de 246 ETAs que geram resíduos, sendo 69 em decantadores e filtros, 176 apenas em filtros e 1 no sistema de dessalinização. O maior número de ETAs convencionais está localizado na região metropolitana do Recife; e a maior produção de lodo foi observada na bacia do Rio Capibaribe, que recebe uma carga entre 50 e 50 mil kg/(m³.dia). Verificou-se que aproximadamente $75 \%$ das ETAs do estado descartam seus resíduos nos corpos hídricos e 22\% no solo, sem qualquer tipo de tratamento. Apenas 3\% realizam o processo de deságue, ainda assim descartam a massa sólida no solo, sem nenhum controle na disposição final.
\end{abstract}

Palavras-chave: estação de tratamento de água; lodo; disposição final; Pernambuco.

\begin{abstract}
This article deals with the generation, quantification and final disposal of the sludge generated at existing Water Treatment Plants (WTPS), operating in the state of Pernambuco. The research was carried out in the period between January 2015 and December 2016 by the collection, systematization and interpretation of data that showed 246 WTPs that generate residues, of which 69 in decanters and filters, 176 only in the filters and one in the desalination system. The largest number of conventiona WTPs is in the metropolitan region of Recife and the highest production of sludge was observed in the Capibaribe river basin, which receives a load of between 50 and 50,000 kg / ( $m^{3}$ day). It was verified that approximately $75 \%$ of the state's WTPs discard their residues in water bodies and $22 \%$ in the soil, without any kind of treatment. Only 3\% perform the degassing process, yet discarding the solid mass in the soil, without any control at the final disposal of the same.
\end{abstract}

Keywords: water treatment plant; sludge; final disposal; Pernambuco.

\section{INTRODUÇÃO}

Para Gheyi et al. (2012), a crise na disponibilidade de água, em termos quantitativos e qualitativos, é consequência do mundo em mudança, no qual o crescimento populacional e a poluição ambiental têm andado juntos. A quantidade e a qualidade da água são influenciadas por diversos fatores, tais como: clima, geografia, topografia, geologia e, principalmente, pelas atividades humanas. Os efeitos adversos que as atividades antrópicas têm exercido sobre os mananciais de abastecimento impõem ameaças à saúde humana, exigindo o uso de tecnologias de tratamento de água e dos resíduos líquidos e sólidos oriundos desse tratamento.
Do ponto de vista do abastecimento de água, o uso de tecnologias mais específicas e com maior eficiência no tratamento, como a coagulação, geralmente está associado ao maior consumo de produtos químicos, gerando um maior volume de resíduos, constituídos por sólidos e precipitados químicos, que compõem uma massa de partículas orgânicas e inorgânicas, densa e viscosa, denominada lodo de estação de tratamento de água (ETA) (SILVA et al., 2012). Esse resíduo é classificado, de acordo com a Norma Brasileira (NBR) 10004 (ABNT, 2004), como um resíduo sólido não perigoso e não inerte. Na Lei Federal no ${ }^{\circ} 11.445$, de 5 de janeiro de 2007, estão estabelecidas as diretrizes nacionais para

Universidade Federal de Pernambuco - Recife (PE), Brasil.

${ }^{2}$ Bioresources, Bioremediation and Biorefinery Group, Centre of Biological Engineering - Braga, Portugal.

*Autor correspondente: mottas@ufpe.br

Recebido: 16/03/2017 - Aceito: 28/05/2018 - Reg. ABES: 175810 
o manejo adequado desse lodo, com vistas à proteção da saúde pública e do meio ambiente (BRASIL, 2007). Nesse contexto, destacam-se a produção, o tratamento e a disposição adequada dos lodos gerados nas ETAs, problemática que afeta todo o Brasil e, principalmente, as regiões norte e nordeste. Segundo Achon, Barroso e Cordeiro (2013), a disposição inadequada desses resíduos contraria a legislação vigente, pois provoca impactos ambientais negativos.

Segundo Molina (2010), no Brasil, a prática comum da maioria das ETAs em operação é o lançamento de seus resíduos sem nenhum tipo de tratamento prévio, nos corpos hídricos ou terrenos próximos às estações. Essa conduta é responsável por impactos tais como: aumento da concentração de metais, principalmente alumínio $(\mathrm{Al})$ e ferro $(\mathrm{Fe})$ e da concentração de sólidos em suspensão; alteração no ciclo de nutrientes, principalmente fósforo $(\mathrm{P})$; desenvolvimento de condições anaeróbias em águas estacionárias ou de baixa velocidade; aumento da turbidez e cor, mudança na composição química; assoreamento dos corpos receptores, pelo aumento de sólidos sedimentáveis; possibilidade de contaminação do lençol freático, dentre outros.

Achon, Barroso e Cordeiro (2013) citam que a sedimentação do lodo de ETA sobre a camada bentônica pode inibir o crescimento de várias espécies de peixes e outros organismos aquáticos. Nessa mesma linha, Mert et al. (2014) explicam que os peixes absorvem metais durante a ingestão de alimentos, os quais ficam retidos em suas vísceras e tecido muscular, passando para o homem pela cadeia alimentar.

Quando o lodo é disposto diretamente no solo, a principal preocupação é quanto à toxicidade do $\mathrm{Al}$ disponível, pois afeta diretamente a produtividade das culturas agrícolas. Segundo Batista et al. (2013), as raízes das plantas são mais sensíveis à toxicidade do $\mathrm{Al}$ disponível, devido não apenas à acumulação preferencial nas raízes, mas também pelo fato de as raízes apresentarem elevada área superficial e baixa densidade e ficarem em contato direto com o solo contaminado, estando assim mais sujeitas aos efeitos do Al.

Em ambientes hídricos, o lodo pode tornar disponíveis íons de $\mathrm{Al}$, que podem vir a comprometer a saúde humana. Pesquisas apontam que portadores da doença de Alzheimer apresentam elevada quantidade de $\mathrm{Al}$ no cérebro, corroborando a ideia de que níveis elevados de $\mathrm{Al}$ podem estar associados a doenças neurológicas, por interferir em diversos processos degenerativos neurofisiológicos (BONDY, 2016).

O primeiro problema, na operação de descarte do lodo, está no seu grande volume, decorrente do elevado teor de água presente. Por essa razão, torna-se necessário que, antes de se definir qualquer forma de disposição, o lodo passe por um tratamento de desidratação ou deságue. Após o devido deságue dos lodos, torna-se necessário definir a melhor alternativa de destino final, cuja forma de disposição tradicional legal é feita em aterros sanitários. Porém, várias pesquisas vêm mostrando o uso benéfico desses resíduos. Para Moreira et al. (2011), esse material pode ser utilizado para a recuperação de áreas degradadas. Já Takada et al. (2013) indicam a sua incorporação em materiais de construção civil; e Padilha (2007) sugere a aplicação para correção de solos agriculturáveis.

De acordo com Moreira et al. (2009), o lodo formado nos decantadores das ETAs tem a mesma composição química dos sedimentos carreados pelas águas dos mananciais de captação, acrescido dos cátions utilizados no processo de floculação. As características do lodo, que variam em função da vazão e da turbidez da água bruta, representam a matéria em suspensão e coloidal dessa água. A concentração total de $\mathrm{Al}$ no lodo de ETA varia em função da dosagem do coagulante que, por sua vez, segue a proporcionalidade das vazões e turbidez da água bruta.

A quantificação do lodo gerado na ETA é fundamental para o planejamento da sua destinação final. Essa quantificação pode ser efetuada através de ensaios, como teste de jarro, fornecendo informações como quantidades de coagulantes e de lodos gerados, assim como tempos de coagulação, floculação e decantação para o dimensionamento da ETA. No que diz respeito às ETAs existentes, além de fórmulas empíricas, pode-se também usar o balanço de massa. Esse método é o mais adequado, pois relaciona a vazão e a concentração de sólidos, na entrada e saída das ETAs existentes (CORNWELL, 2006).

Segundo Katayama et al. (2015), todas as equações empíricas possuem dois componentes: primeiro, a fração dos sólidos da água bruta, que é removida no tratamento e quantificada pela concentração de sólidos em suspensão totais (SST); segundo, os produtos químicos adicionados à água bruta (coagulantes, polímeros, carvão ativado em pó e outros).

Os modelos empíricos para quantificação do lodo gerado em ETA, citados por Dillon (1996), American Water Works Association (AWWA, 1999), Kawamura (1991), Association Francaise Pour Létude Des Eaux (AFEE, 1993) e Cornwell (2006), consideram a turbidez, a vazão da água bruta e a dosagem de coagulante e inserem, também, o parâmetro cor, ligado à particularidade dos períodos chuvosos. Nos períodos chuvosos há aumento significativo na cor e turbidez da água bruta, implicando no aumento da dosagem a ser usada de produtos químicos. Apesar de não tão precisos, existem modelos empíricos para prever a geração de lodos em ETAs, como o modelo AFEE (1993), o qual considera o fenômeno de hidratação, que ocorre na floculação/coagulação, impondo um valor para a molécula de água ligada ao lodo, após o desaguamento.

Dessa forma, a presente pesquisa se propôs a analisar dados existentes relativos à produção e à disposição de lodos de ETAs do estado de Pernambuco, no período de 2009 a 2015, estudando também a distribuição geográfica e a tipologia das ETAs, assim como as destinações finais adotadas, gerenciadas pela Companhia Pernambucana de Saneamento (COMPESA). 


\section{METODOLOGIA}

A base de dados utilizada na pesquisa documental teve como fontes a COMPESA, a Secretaria de Recursos Hídricos e Energéticos (SRHE/PE), a Agência de Regulação de Pernambuco (ARPE), o Instituto Brasileiro de Geografia e Estatística (IBGE), a Empresa Brasileira de Pesquisa Agropecuária (EMBRAPA) e o Sistema Nacional de Informações sobre Saneamento (SNIS).

A área de estudo foi o estado de Pernambuco, localizado geograficamente na Região Nordeste do Brasil, coordenadas $08^{\circ} 04^{\prime}$ S e $37^{\circ} 15^{\prime}$ W. O estado engloba o arquipélago de Fernando de Noronha, com população total de 9.208.550 habitantes (IBGE, 2014) em uma área de $98.937,84 \mathrm{~km}^{2}$, que corresponde a $1,2 \%$ do território brasileiro. É representado, geologicamente, por uma predominância de rochas cristalinas, em $84 \%$ da sua área, sendo 4,4\% na bacia sedimentar. É composto de 13 bacias hidrográficas, seis grupos de bacias de pequenos rios litorâneos, nove grupos de bacias de pequenos rios interiores e uma bacia de pequenos rios que compõem a rede de drenagem de Fernando de Noronha - todos vertentes das bacias do Rio São Francisco e do Oceano Atlântico Oriental (PERNAMBUCO, 2014).

Para caracterizar e quantificar as ETAs existentes no estado, no que diz respeito a fontes geradoras e formas de disposição final do lodo gerado, foram coletados dados de monitoramento na COMPESA e na ARPE, referentes ao período de 2009 a 2015, conforme citado anteriormente. As Figuras 1 e 2 apresentam a localização das ETAS convencionais e compactas estudadas. A quantificação dos lodos gerados nos decantadores das ETAs convencionais do estado de Pernambuco foi estimada por meio de equações descritas em AWWA (1999), Dillon (1996), AFEE (1993), Kawamura (1991) e Cornwell (2006). A escolha desses modelos empíricos teve como base a facilidade de obtenção dos dados de entradas, vazão, dosagem de coagulantes, turbidez e cor da água bruta, que fazem parte do monitoramento diário da água bruta em todas as ETAs operadas pela COMPESA.

O tratamento estatístico dos dados obtidos nos seis modelos foi a estatística descritiva, com a verificação do intervalo de confiança. Foram determinados: média, desvio padrão, mediana e variância. Os dados fora do intervalo de confiança de $95 \%$ foram descartados.

A pesquisa contou com o apoio de um Sistema de Informações Geográficas (SIG), estruturado com informações relevantes e primordiais para o desenvolvimento do trabalho. As coordenadas geográficas das ETAs foram obtidas na COMPESA e na ARPE e através do Google Earth, juntamente com as respectivas características: tipo, nome, município, origem, disposição do resíduo, média anual de turbidez, média anual de cor, dosagem de coagulante, vazão e carga de resíduo. Ao final, foram organizadas em planilhas eletrônicas e, posteriormente, adicionadas ao SIG.

A elaboração do mapa de carga de lodo produzido pelas ETAs foi realizada com base nos valores empíricos encontrados com o modelo de AFEE (1993), modelo 3, que avalia a produção de lodo em função do coagulante usado, remoção da turbidez e cor da água bruta. Esse padrão apresentou o menor coeficiente de variação, tendo sido, como consequência, o modelo no qual os resultados apresentaram o menor grau de dispersão.

\section{RESULTADOS E DISCUSSÃO}

\section{Características físico-químicas dos lodos}

A Tabela 1 apresenta as faixas de valores para os lodos estudados, com os valores máximos e mínimos para cada parâmetro. Pode-se observar que a demanda química de oxigênio (DQO) para as ETAs convencionais variaram cerca de $23 \%$, enquanto o seu valor médio em relação às compactas apresentaram uma diferença superior a $90 \%$. A turbidez foi o parâmetro que apresentou maior amplitude de valores em relação às ETAs convencionais, sendo o valor máximo 66 vezes o valor mínimo. A umidade não flutuou muito, com uma amplitude de apenas $2,8 \%$ para as convencionais e valores um pouco maiores para as compactas (2,54\% acima). Os valores obtidos estão acima da faixa verificada por Ritcher (2011), cuja DQO dos lodos variou de 30 a $5.000 \mathrm{mg} / \mathrm{L}$. Todavia o autor citado trabalhou apenas com dados de ETAs do estado de São Paulo.

Os sólidos são predominantemente inorgânicos (fixos), fato esperado uma vez que os principais componentes removidos são argilas, siltes, areia e outros componentes inorgânicos. Todavia foi observado, para a faixa alta de sólidos totais, um incremento significativo da fração orgânica, podendo ser oriunda de microrganismos, algas ou fitoplânctons, entre outros, além da poluição carbonácea oriunda do descarte de efluentes e rejeitos não tratados adequadamente nos corpos hídricos.

Em relação aos metais, percebe-se a elevada concentração de $\mathrm{Al}$, oriunda dos agentes coagulantes, seguida do Fe, que tem sua origem principalmente do solo, uma vez que no estado não são usados coagulantes a base de ferro.

\section{Disposição das estações de tratamento de água: tecnologias de tratamento de água que produzem resíduos}

De acordo com o estudo realizado, existem no estado de Pernambuco 246 ETAs, sendo 69 do tipo convencional, que geram resíduos nos decantadores e filtros, e 177 do tipo não convencional, denominadas compactas. Destas, 176 geram lodo apenas durante as lavagens dos filtros, enquanto uma utiliza a tecnologia de dessalinização, por se tratar de um sistema que tem como fonte de abastecimento a água do mar. Por se tratar de um lodo altamente salino, o resíduo gerado nessa estação é disposto no oceano. Essa prática, de acordo com Porto et al. (2004), é usada nos países desenvolvidos, onde os detritos são 


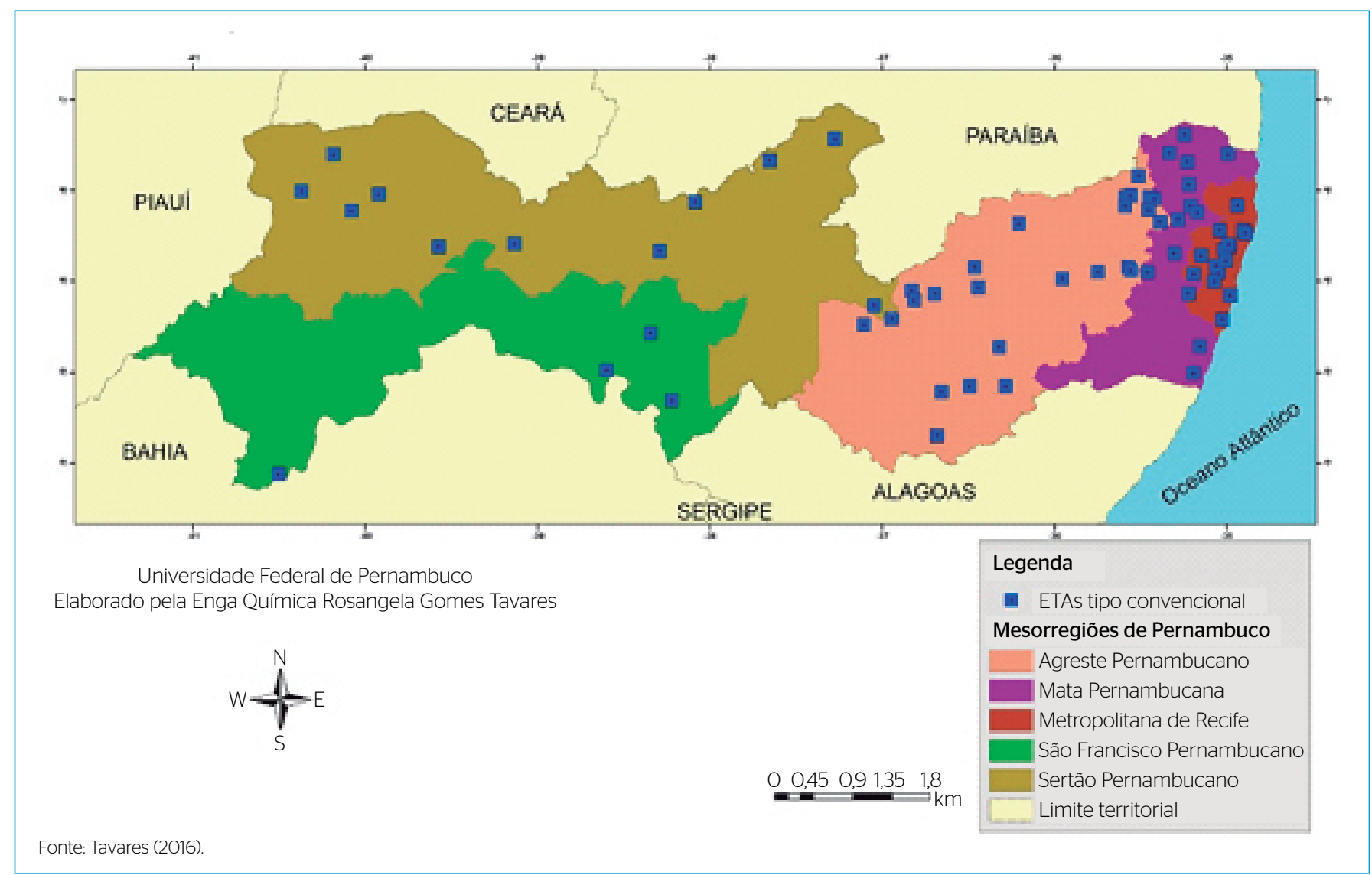

Figura 1 - Localização regional das estações de tratamento de água (ETAs) convencionais no estado de Pernambuco.

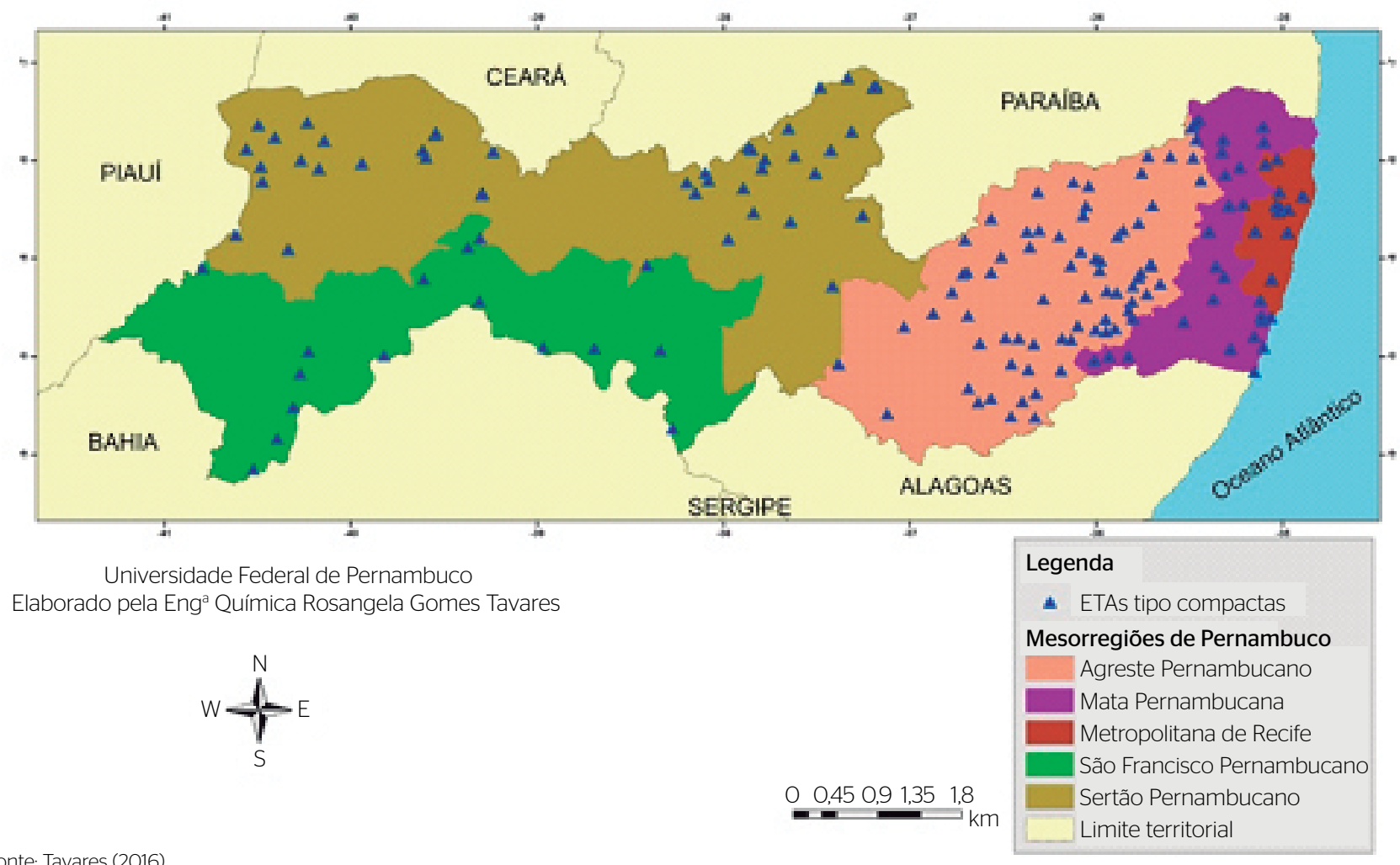

Figura 2 - Localização regional das estações de tratamento de água (ETAs) compactas no estado de Pernambuco. 
lançados no oceano, ou injetados em poços profundos. Para Lattemann e Höpner (2008), o processo de descarte dos resíduos no mar, como é realizado na ETA de Fernando de Noronha, apresenta a desvantagem de impactar os organismos marinhos que habitam o local de descarga, por conta da frequência e intensidade de exposição à solução com salinidade mais elevada, quando não é observada a adequação das descargas em função das correntes oceânicas.

Existem, ainda, as ETAs que tratam a água de fonte subterrânea, utilizando apenas a desinfecção. Nessas, não há geração de resíduo, por isso, não foram incluídas nesta pesquisa. A Tabela 2 mostra a distribuição das ETAs, por região de desenvolvimento, no estado de Pernambuco, onde a maioria é do tipo compacta. Segundo Libâneo (2010), essa é uma alternativa para tratar água com turbidez baixa, no máximo 100 uT, em locais onde não há área disponível e por ser de menor custo (até $50 \%$ de uma ETA convencional). Durante o período de observação e coleta de dados, os valores máximo, mínimo e médio de turbidez da água afluente a essas estações foram 92,96; 1,4 e 20,34 uT, respectivamente, sendo a vazão máxima encontrada para as ETAs compactas de $70 \mathrm{~L} / \mathrm{s}$.

Das ETAs compactas, foi identificada a predominância do tipo dupla filtração. Essa tecnologia é uma das mais usadas, principalmente por garantir eficiência no tratamento, mesmo para água com turbidez elevada (até $300 \mathrm{uT}$ ), sendo capaz de produzir água filtrada com turbidez menor do que 0,5 uT. A Tabela 3 apresenta o índice de quantitativo de ETAs, por tipo de tratamento adotado no estado, mostrando que o modelo mais comum é a dupla filtração, que corresponde a 32\% do total de ETAs, índice superior ao de estações convencionais, correspondendo a $28 \%$.
As 177 ETAs compactas existentes no estado possuem vazões inferiores a $100 \mathrm{~L} / \mathrm{s}$, sendo a menor encontrada com 3,6 e a maior com $66,8 \mathrm{~L} / \mathrm{s}$. Enquanto as ETAs convencionais, existentes no estado de Pernambuco, apresentam vazões que variam de 100 até $5 \mathrm{mil} \mathrm{L} / \mathrm{s}$.

As ETAs com vazão superior a mil L/s estão localizadas na região metropolitana, onde se encontra a maior concentração populacional e também a maior disponibilidade hídrica. De acordo com o Atlas Brasil (ANA, 2010), o Nordeste Oriental possuía disponibilidade hídrica $\left(\mathrm{Q}_{95}\right)$ de $91 \mathrm{~m}^{3} / \mathrm{s}$. Enquanto o Relatório de Conjuntura dos Recursos Hídricos no Brasil (ANA, 2017) apontou um aumento para $218 \mathrm{~m}^{3} / \mathrm{s}$. Pernambuco (1998) indicou que o estado possuía a menor disponibilidade, com apenas $62,8 \mathrm{~m}^{3} / \mathrm{s}$ superficial e $4,7 \mathrm{~m}^{3} / \mathrm{s}$ subterrânea. Desses recursos, $80 \%$ são distribuídos na região metropolitana e Zona da Mata, enquanto os $20 \%$ restantes atendem ao agreste e ao

Tabela 2 - Número e distribuição geográfica das estações de tratamento de água em operação no estado de Pernambuco, 2015.

\begin{tabular}{l|c|c|c}
\multirow{2}{*}{$\begin{array}{l}\text { Região de } \\
\text { desenvolvimento }\end{array}$} & \multicolumn{3}{|c}{ Estações de tratamento } \\
\cline { 2 - 4 } & Convencional & Compacta & $\begin{array}{c}\text { Sistema com } \\
\text { dessalinizador }\end{array}$ \\
\hline Região Metropolitana & 15 & 12 & - \\
\hline Zona da Mata & 13 & 27 & - \\
\hline Agreste & 25 & 74 & - \\
\hline Sertão & 12 & 46 & - \\
\hline Sertões do São Francisco & 4 & 16 & - \\
\hline Fernando de Noronha & - & 1 & 1 \\
\hline Total & 69 & 176 & 1 \\
\hline
\end{tabular}

Tabela 1 - Características físico-químicas dos lodos das estações de tratamento de água (ETAs) estudadas.

\begin{tabular}{|c|c|c|c|c|}
\hline \multirow{2}{*}{ Parâmetros } & \multicolumn{2}{|c|}{ ETAs convencionais } & \multicolumn{2}{|c|}{ ETAs compactas } \\
\hline & Valor mínimo & Valor máximo & Valor mínimo & Valor máximo \\
\hline $\mathrm{Q}(\mathrm{L} / \mathrm{s})$ & 100 & 5.000 & 3,7 & 66,8 \\
\hline Turbidez (UT) & 80 & 5.332 & 25 & 142 \\
\hline $\mathrm{DQO}(\mathrm{mg} / \mathrm{L})$ & 11.627 & 15.120 & 138 & 403 \\
\hline $\mathrm{ST}(\mathrm{mg} / \mathrm{L})$ & 10.699 & 31.932 & 362 & 1411 \\
\hline STF (mg/L) & 24.367 & 5.733 & 249 & 897 \\
\hline STV (mg/L) & 8.204 & 4.966 & 102 & 514 \\
\hline $\mathrm{Cu}(\mathrm{mg} / \mathrm{L})$ & 0,0 & 0,2 & 0,0 & 0,0 \\
\hline $\mathrm{Pb}(\mathrm{mg} / \mathrm{L})$ & 0,0 & 0,2 & 0,0 & 0,0 \\
\hline $\mathrm{Al}(\mathrm{mg} / \mathrm{L})$ & 733 & 2.405 & 18 & 35 \\
\hline
\end{tabular}

Fonte: adaptado de Araújo (2006) e Tavares (2003).

Q: vazão; CE: condutividade elétrica; DQO: demanda química de oxigênio; ST: sólidos totais; STF: sólidos totais fixos; STV: sólidos totais voláteis. 
sertão pernambucanos. Segundo o IBGE (2010), 43\% da população do estado vive na região metropolitana, $14 \%$ na Zona da Mata, $24 \%$ no Agreste, $13 \%$ no Sertão e $5 \%$ no Sertão do São Francisco, onde há o menor número de ETAs: quatro convencionais e 16 compactas.

\section{Quantificação dos resíduos de estações de tratamento de água}

A quantificação do lodo gerado, em $\mathrm{kg}$ de lodo/( $\mathrm{m}^{3}$.dia), nos decantadores das 69 ETAs convencionais e nos filtros das 176 ETAs compactas, foi realizada com a utilização do modelo 1 (AWWA, 1999), modelo 2 (DILLON, 1996), modelo 3 (AFEE, 1993), modelo 4 (KAWAMURA, 1991) e modelo 5 (CORNWELL, 2006). Os valores de produção de lodo em ambos os tipos de tratamento da água (convencional e compacta), estimados utilizando esses modelos, apresentaram resultados semelhantes quando analisado o grau de dispersão, avaliando-se o coeficiente de variação (Tabela 4).

A Tabela 5 mostra a produção média de lodo, segundo os modelos por região demográfica do estado de Pernambuco.

A diferença significativa de lodo gerado, $\mathrm{em} \mathrm{kg} /\left(\mathrm{m}^{3}\right.$.dia $)$, conforme os resultados mencionados anteriormente, entre os resultados estimados utilizando-se o modelo 1 e os modelos 2, 3, 4 e 5 pode ser causada pelo fato de, com a utilização do modelo 1 , se admitir uma produção de lodo diretamente relacionada com a turbidez da água bruta e a sua vazão, sem considerar outros fatores, como dosagem de produtos químicos (coagulante e polímero) e cor da água bruta. Katayama (2015), que também utilizou esses modelos empíricos para estimar a produção de lodo em ETAs convencionais, operadas pela Companhia de Saneamento Básico do estado de São Paulo (SABESP), encontrou, da mesma forma, menor valor ao utilizar o modelo 1. Esse modelo subestima a produção de lodo por considerar poucos parâmetros/variáveis do processo de coagulação e de qualidade da água. Da mesma forma, Ribeiro (2007) determinou a quantidade de lodo gerado em uma estação convencional, ETA Itabirito, em Minas Gerais, pelos mesmos modelos empíricos, comparando com o valor encontrado pelo balanço de massa.
O autor escolheu o modelo 3, com base na precisão e menor variação dos resultados. Para Saron e Leite (2001), o modelo 1 enquadra-se para ETAs que não realizam a coagulação, apenas fazem a filtração, não sendo o caso das ETAs aqui estudadas. A variabilidade dos demais modelos está associada ao tratamento que cada autor atribuiu à relação sólido suspenso e turbidez, além da inclusão ou não do parâmetro cor.

Para se avaliar a produção de lodo por bacias hidrográficas do estado de Pernambuco, foram consideradas as 13 bacias hidrográficas, seis bacias de pequenos rios litorâneos e nove bacias de pequenos rios interiores, conforme mostram a Figura 3 e a Tabela 6 .

Na Figura 3 é possível verificar que as maiores cargas de lodo estão na Região Metropolitana de Recife, onde há elevada densidade populacional e onde estão os municípios com maior produto interno bruto (PIB), necessitando assim de uma boa gestão desses resíduos.

Pode-se ainda observar (Figura 3) que na região do Moxotó e do Pajeú há uma redução na carga de lodo, em razão da densidade populacional mais baixa aliada ao fornecimento de água subterrânea de origem fissural. Em relação às compactas, vê-se uma região com carga mais elevada no meio da região do Moxotó, no município de Betânia. Esse cenário vem do fato de cerca de $90 \%$ da água subterrânea desse município ser salobra/salina, aliada à má qualidade da água superficial.

Observa-se, na Tabela 6, que a bacia do Rio Capibaribe possui o maior número de ETAs, totalizando 40, entre convencionais e compactas, com produção diária entre 50 e $100 \mathrm{~kg} / \mathrm{m}^{3}$ para as compactas, e entre $5 \mathrm{mil} \mathrm{e} 50 \mathrm{mil} \mathrm{kg} / \mathrm{m}^{3}$, para as convencionais. A bacia do grupo de pequenos rios litorâneos, GL 2, apesar de ter apenas 10 estações, está entre essas: a ETA Pirapama, cuja produção diária é superior a

Tabela 4 - Grau de dispersão em função do valor do coeficiente de variação.

\begin{tabular}{c|c} 
Valor do coeficiente de variação & Grau de dispersão \\
\hline$<0,50$ & Baixo \\
\hline $0,50-1,00$ & Médio \\
\hline$>1,00$ & Alto \\
\hline
\end{tabular}

Tabela 3 - Tipos de tratamento, características e índice de adoção* no estado de Pernambuco.

\begin{tabular}{|c|c|c|c|}
\hline Tipo de tratamento & Características & Índice (i) em Pernambuco (\%) & Total \\
\hline Convencional & $\begin{array}{l}\text { Coagulação, floculação, decantação, } \\
\text { filtração e desinfecção }\end{array}$ & 28,5 & 28,5 \\
\hline Compacta tipo filtração direta ascendente & $\begin{array}{l}\text { Coagulação por adsorção-neutralização } \\
\text { de cargas e filtração de fluxo ascendente }\end{array}$ & 17,2 & \multirow{3}{*}{71,0} \\
\hline Compacta tipo filtração direta descendente & $\begin{array}{l}\text { Coagulação por adsorção-neutralização } \\
\text { de cargas e filtração de fluxo descendente }\end{array}$ & 21,7 & \\
\hline Compacta tipo dupla filtração & $\begin{array}{l}\text { Coagulação por adsorção-neutralização de cargas e } \\
\text { dupla filtração, fluxo ascendente e descendente }\end{array}$ & 32,1 & \\
\hline $\begin{array}{l}\text { Compacta tipo separação por membrana } \\
\text { (MF, UF, NF, OR, D, ED e PV) }\end{array}$ & $\begin{array}{l}\text { Processo físico-químico de retirada de sais da água } \\
\text { por meio de membranas osmóticas sintéticas }\end{array}$ & 0,5 & 0,5 \\
\hline
\end{tabular}

*Indice de adoção é a porcentagem do tipo de tratamento em relação ao total; MF: microfiltração; UF: ultrafiltração; NF: nanofiltração; OR: osmose reversa; D: diálise; ED: eletrodiálise; PV: pervaporação. 
$150 \mathrm{mil} \mathrm{kg} / \mathrm{m}^{3}$ dia; as bacias do grupo de pequenos rios litorâneos, GL 6; e dos pequenos rios interiores, GI 2 e GI 6, não possuem ETA em suas áreas, não recebendo esse tipo de resíduo.

\section{Disposição final}

A prática de descarte do lodo de ETA no meio ambiente, quer seja no corpo hídrico, quer no solo, precisa ser modificada em função da poluição e degradação que acarreta no local do destino final. Entre as práticas adotadas, exploradas vastamente pela literatura, destacam-se: aterros sanitários, aterros exclusivos, gerenciamento em conjunto com o lodo de estação de tratamento de esgoto (ETE), codisposição com biossólido, aplicação controlada no solo destinada à recuperação de áreas degradadas e, por fim, o aproveitamento em diversas indústrias, com destaque no ramo da construção civil. Porém, no estado de Pernambuco, essas propostas ainda são muito discretas e a prática diária contraria duramente a legislação, como a Política Nacional de Recursos Hídricos (Brasil, 1997), que veda o lançamento dos lodos das ETAs nos corpos hídricos, ao processo de outorga, e a Lei de Crimes Ambientais (BRASIL, 1998), que possibilita a punição nas esferas civil, administrativa e penal.

A Tabela 7 apresenta o número de ETAs no estado de Pernambuco que descartam seus resíduos nos corpos hídricos e no solo, como também o número de estações que realizam algum tipo de tratamento de deságue.

A Tabela 7 mostra que 75\% dos resíduos de ETAs são dispostos diretamente em corpos hídricos, valor muito superior ao que encontramos na literatura referente à gestão adotada por países desenvolvidos como Estados Unidos, que descartam 11\% em corpos hídricos; Reino Unido, apenas 2\%; e outros países como Alemanha, França e Japão, que não realizam nenhum descarte nos corpos hídricos (ALAMINO, 2010).

Os valores da concentração de $\mathrm{Al}$ no lodo estudado variaram de 18 a $2.405 \mathrm{~g} / \mathrm{L}$. Esses valores podem comprometer a fertilidade do solo e contaminá-lo, afetar a flora e até mesmo o lençol freático. Reis et al. (2007) alertam que o lançamento do lodo diretamente em corpos hídricos pode levar ao aumento da concentração de alguns elementos, tais como $\mathrm{Al}, \mathrm{Ca}, \mathrm{Fe}, \mathrm{K}, \mathrm{Mn}, \mathrm{Mg}$ e $\mathrm{Na}$, além das alterações nas características dos sedimentos, redução do $\mathrm{pH}$ da água, liberação de odores, redução da quantidade de oxigênio dissolvido no corpo hídrico, toxidade crônica aos organismos aquáticos e impacto visual.

Quanto à disposição no solo, 22\% das ETAs do estado realizam essa prática. Para Tsutiya e Hirata (2001), a aplicação de lodos de ETAs no campo apresenta alguns benefícios em solos agrícolas, tais como: melhoria estrutural; ajuste de $\mathrm{pH}$; adição de traços de minerais; aumento da capacidade de retenção de água; e melhoria das condições de aeração do terreno. Contrariamente, para Basso et al. (2003), em solos agricultáveis pode ocorrer a indisponibilização do $\mathrm{P}$, presente no solo, à planta. Para o autor, a toxicidade do $\mathrm{Al}$ no solo está associada ao $\mathrm{pH}$, uma vez que em solos com $\mathrm{pH}$ inferior a 5,5 o Al se apresenta na forma trocável, potencialmente tóxico; e em solos com $\mathrm{pH}$ acima de 5,5 o Al se encontra em formas precipitadas.

Os solos do estado de Pernambuco possuem altas parcelas de argilas e, portanto, geralmente são ácidos. Com isso, a disposição do lodo com altas concentrações de $\mathrm{Al}$ no terreno favorece o seu aprisionamento, assim como a diminuição da disponibilidade de nutrientes, principalmente o P. Para Gonçalves et al. (2017), é necessária a redução no teor de água dos lodos de ETA, quando a finalidade for a disposição no solo. O excesso de água no lodo, que usa coagulante a base de $\mathrm{Al}$, pode acarretar a produção de ácidos graxos voláteis, reduzindo o pH do meio e favorecendo a lixiviação do Al, como espécie iônica.

As ETAs que possuem tratamento de deságue, sendo do tipo filtro prensa (1 ETA), lagoa de decantação (6) e dispositivos tubulares de geotêxtil (bags) (2), recirculam a água lixiviada. Porém os resíduos sólidos continuam sem o destino adequado. Com exceção das duas estações que usam bags como forma de deságue, as demais dispõem

Tabela 5 - Produção média de lodo por região demográfica do estado de Pernambuco.

\begin{tabular}{|c|c|c|c|c|c|c|c|c|}
\hline Tipo de ETA & Região demográfica & $\begin{array}{l}\text { N. de } \\
\text { ETAs }\end{array}$ & Faixa de vazão (L/s) & Modelo 1 & Modelo 2 & Modelo 3 & Modelo 4 & Modelo 5 \\
\hline \multirow{3}{*}{ Convencional } & Região Metropolitana & 15 & $46-5130$ & $7.585,13$ & $21.800,07$ & $16.986,07$ & $18.832,27$ & $20.050,27$ \\
\hline & Agreste & 25 & $20-880$ & 658,92 & $2.054,12$ & $1.368,36$ & $1.488,32$ & $1.661,84$ \\
\hline & Sertão & 12 & $17-183$ & 234,50 & 677,17 & 390,75 & 435,25 & 507,75 \\
\hline \multirow{4}{*}{ Compacta } & Região Metropolitana & 14 & $8-28$ & 60,34 & 132,61 & 96,50 & 106,65 & 115,79 \\
\hline & Zona da Mata & 25 & $6-67$ & 86,02 & 37,18 & 92,78 & 53,70 & 54,14 \\
\hline & Agreste & 80 & $4-48$ & 78,03 & 29,74 & 75,90 & 44,43 & 46,66 \\
\hline & Sertão & 48 & $4-59$ & 79,18 & 31,40 & 85,48 & 46,74 & 50,31 \\
\hline
\end{tabular}

ETA: estação de tratamento de água. 


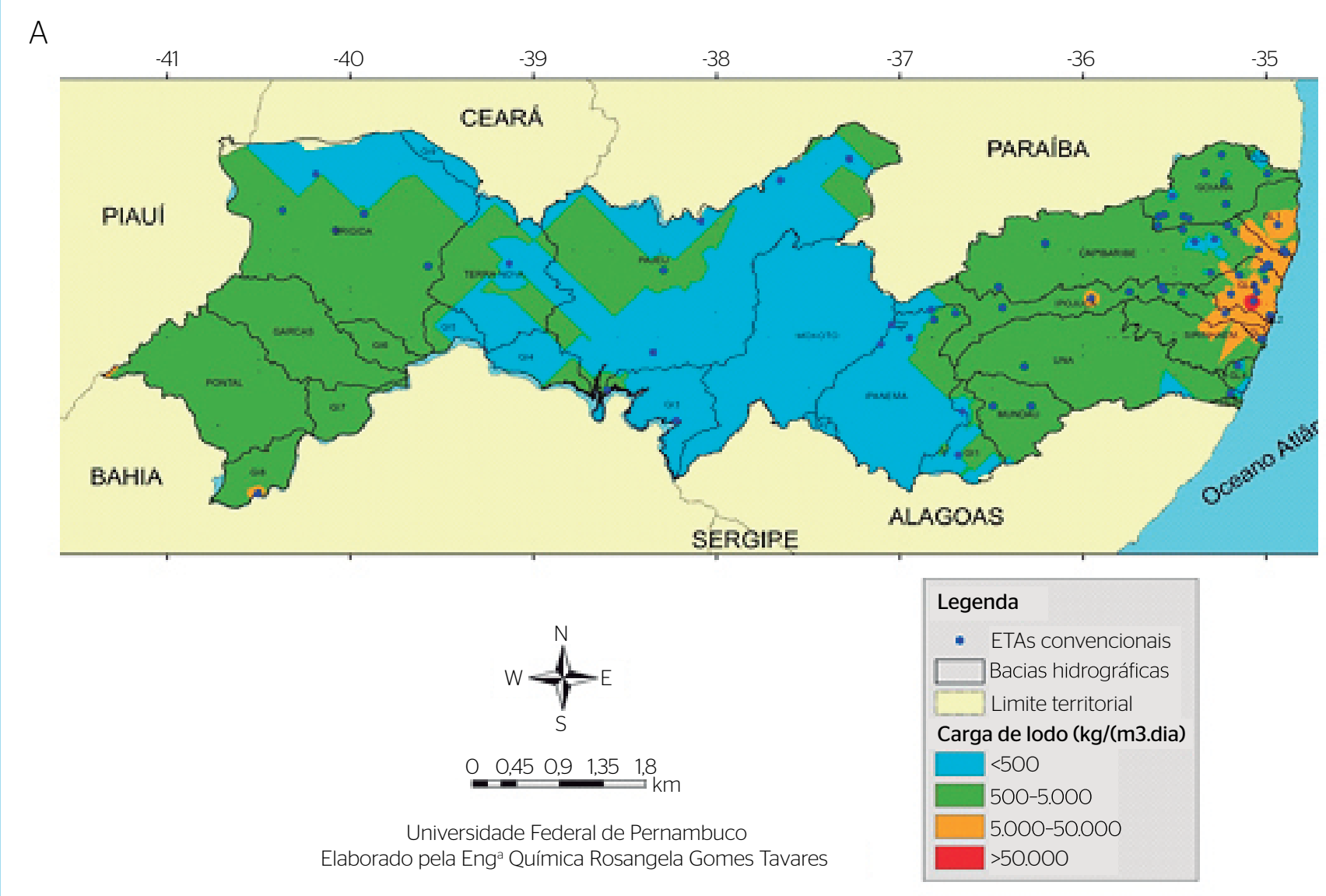

B
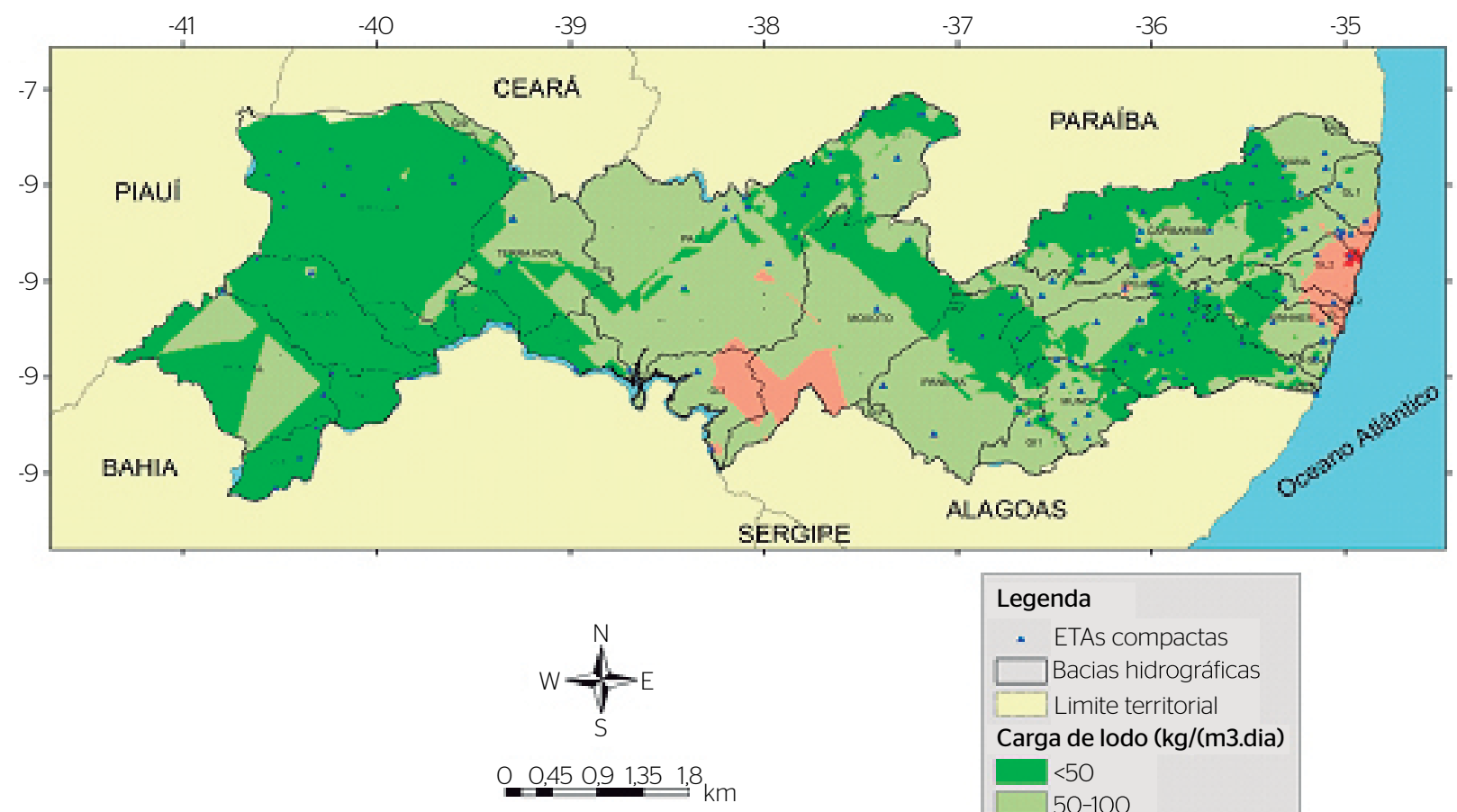

Universidade Federal de Pernambuco

Elaborado pela Enga Química Rosangela Gomes Tavares

Legenda
ETAs compactas
$\square$ Bacias hidrográficas
$\square$ Limite territorial
Carga de lodo (kg/(m3.dia)
$<50$
$50-100$
$100-150$
$>150$

Figura 3 - Disposição das estações de tratamento de água (ETAs) convencionais (A) e compactas (B) no estado de Pernambuco em função da carga de lodo por bacia hidrográfica, 2015. 
o resíduo sólido no terreno próximo à estação. As ETAs Gurjaú e Botafogo, ambas localizadas na Região Metropolitana de Recife, retêm seus lodos nos bags.

\section{CONSIDERAÇÕES FINAIS}

De acordo com a análise dos dados de distribuição geográfica das ETAs no estado de Pernambuco, foram identificadas 246 ETAs geradoras de resíduos, sendo 69 em decantadores e filtros, 176 apenas nos filtros e 1 no sistema de dessalinização. O tipo de ETA mais comum no estado é a compacta com dupla filtração, que corresponde a 32\% do total de ETAs existentes, seguido das convencionais, com $28 \%$.
O maior número de ETAs convencionais está localizado na região metropolitana, onde ocorre a maior disponibilidade hídrica e população atendida: 80 e 43\%, respectivamente. A região de desenvolvimento do Agreste e Sertão concentra as ETAs com menores vazões, predominando

Tabela 7 - Formas de disposição final dos resíduos de estações de tratamento de água no estado de Pernambuco.

\begin{tabular}{l|c|c|c}
$\begin{array}{l}\text { Estações de tratamento } \\
\text { de água }\end{array}$ & $\begin{array}{c}\text { Descarte no } \\
\text { corpo hídrico }\end{array}$ & $\begin{array}{c}\text { Descarte } \\
\text { no solo }\end{array}$ & $\begin{array}{c}\text { Processo } \\
\text { de deságue }\end{array}$ \\
\hline Convencionais & 49 & 15 & 5 \\
\hline Não convencionais & 135 & 38 & 4 \\
\hline Total & $184(75 \%)$ & $53(22 \%)$ & $9(3 \%)$ \\
\hline
\end{tabular}

Tabela 6 - Distribuição das estações de tratamento de água (ETAs) por bacias hidrográficas no estado de Pernambuco, 2016.

\begin{tabular}{|c|c|c|c|c|c|}
\hline \multirow{3}{*}{ Bacia hidrográfica } & \multirow{3}{*}{$\begin{array}{l}\text { Área superficial } \\
\text { do estado (\%) }\end{array}$} & \multicolumn{4}{|c|}{ Estação de tratamento de água } \\
\hline & & \multicolumn{2}{|c|}{ Compacta } & \multicolumn{2}{|c|}{ Convencional } \\
\hline & & N. de ETA & $\begin{array}{l}\text { Carga de lodo } \\
\left(\mathrm{kg} /\left(\mathrm{m}^{3} . \text { dia }\right)\right)\end{array}$ & N. de ETA & $\begin{array}{c}\text { Carga de lodo } \\
\left(\mathrm{kg} /\left(\mathrm{m}^{3} . \text { dia }\right)\right)\end{array}$ \\
\hline Brígida & 13,73 & 15 & $\leq 50$ & 5 & $500-5.000$ \\
\hline Capibaribe & 7,58 & 29 & $50-100$ & 11 & $500-5.000$ \\
\hline GI 2 & 0,16 & O & 0 & 0 & O \\
\hline GI 3 & 2,32 & 2 & $50-100$ & 2 & $\leq 500$ \\
\hline Gl 4 & 1,33 & 2 & $\leq 50$ & $\mathrm{O}$ & $\mathrm{O}$ \\
\hline GI 5 & 0,72 & 1 & $\leq 500$ & O & O \\
\hline Gl 8 & 1,32 & 3 & $\leq 50$ & 2 & $500-5.000$ \\
\hline GI 9 & 0,55 & O & O & O & O \\
\hline GL 1 & 1,21 & 4 & $50-100$ & 3 & $500-5.000$ \\
\hline GL 2 & 1,29 & 2 & $100-150$ & 8 & $5.000-50.000$ \\
\hline GL 3 & 0,13 & O & 0 & 1 & $5.000-50.000$ \\
\hline GL 4 & 0,30 & 2 & $50-100$ & 1 & $500-5.000$ \\
\hline GL 5 & 0,07 & 1 & $50-100$ & 0 & O \\
\hline GL 6 & 0,09 & 0 & 0 & 0 & 0 \\
\hline Goiana & 2,90 & 12 & $50-100$ & 11 & $500-5.000$ \\
\hline Pontal & 6,12 & 2 & $\leq 50$ & O & O \\
\hline Sirinhaém & 2,13 & 9 & $50-100$ & 0 & 0 \\
\hline Terra Nova & 4,97 & 5 & $50-100$ & 1 & $\leq 500$ \\
\hline Una & 6,37 & 28 & $\leq 50$ & 2 & $500-5.000$ \\
\hline
\end{tabular}


as do tipo compacta, que tratam menor volume de água, com turbidez relativamente baixa e, portanto, geram menor carga de lodo.

Quanto à produção do lodo, foi observado que a bacia do Rio Capibaribe recebe a maior carga diária, entre 50 e $50 \mathrm{mil} \mathrm{kg} / \mathrm{m}^{3}$, de ETAs compactas e convencionais. Todavia a bacia GL 2 (grupo dos pequenos rios litorâneos) possui a maior ETA, a ETA Pirapama, que chega a tratar $5.130 \mathrm{~L} / \mathrm{s}$, gerando mais de $150 \mathrm{mil} \mathrm{kg} / \mathrm{m}^{3}$ de lodo por dia.

No que diz respeito à disposição final dos resíduos das ETAs do estado pernambucano, verificamos que 75\% descartam seus resíduos nos corpos hídricos e $22 \%$ no solo, esse último, sem qualquer tipo de tratamento. Apesar de 9\% realizarem o processo de deságue, ainda descartam, na terra, a massa sólida, sem nenhuma gestão.

\section{FONTE DE FINANCIAMENTO}

Conselho Nacional de Desenvolvimento Científico e Tecnológico (CNPq), Fundação de Amparo à Ciência e Tecnologia do Estado de Pernambuco (FACEPE), Coordenação de Aperfeiçoamento de Pessoal de Nível Superior (CAPES), Universidade Federal Rural de Pernambuco (UFRPE), Universidade Federal de Pernambuco (UFPE), COMPESA, ARPE

\section{REFERÊNCIAS}

ACHON, C.L.; BARROSO, M.M.; CORDEIRO, J.S. (2013) Resíduos de estações de tratamento de água e a ISO 24512: desafio do saneamento brasileiro. Engenharia Sanitária e Ambiental, v. 18, n. 2, p. 115-122. http://dx.doi.org/10.1590/S1413-41522013000200003

AGÊNCIA NACIONAL DE ÁGUAS (ANA). (2010) Atlas Brasil: abastecimento urbano de água - panorama nacional. Engecorps / Cobrape - Brasília: Agência Nacional de Águas/ Engecorps/Cobrape.

AGÊNCIA NACIONAL DE ÁGUAS (ANA). (2017) Conjuntura dos recursos hídricos no Brasil 2017: relatório pleno. Brasília: Agência Nacional de Águas. 169 p.

ALAMINO, R.C.J. (2010) A utilização de lodo de esgoto como alternativa sustentável na recuperação de solos degradados: Viabilidade, avaliação e biodisponibilidade de metais. $221 \mathrm{f}$. Tese (Doutorado em Geologia) - Programa de Pós-Graduação em Geologia, Instituto de Geociências, Universidade Federal do Rio de Janeiro, Rio de Janeiro.

AMERICAN WATER WORKS ASSOCIATION (AWWA). (1999) Water quality and treatment: a handbook of community water supplies. 5. ed. Nova York: McGraw-Hill.

ARAÚJO, A.M. de. (2006) Avaliação operacional e características do lodo gerado na indústria da água do litoral sul de Pernambuco. 136f. Dissertação (Mestrado) - Programa de Pós-Graduação em Tecnologia Ambiental e Recursos Hídricos, Universidade Federal de Pernambuco, Recife.

ASSOCIAÇÃO BRASILEIRA DE NORMAS TÉCNICAS (ABNT). (2O04) NBR-10004: Resíduos sólidos - Classificação. 2. ed. Rio de Janeiro: ABNT.

ASSOCIATION FRANCAISE POUR L'ÉTUDE DES EAUX (AFEE). (1993) Traitement des boues de stations de production d'eau potable. França: AFEE.

BASSO, L.H.M.; GONÇALVES, A.N.; SILVEIRA, L.V.A.; LIMA, G.P.P. (2003) Aluminum effect on Eucalyptus grandis $\times$ E. urophylla shoots growth in vitro. Scientia Forestalis, n. 63, p. 167-177.
BATISTA, M.F.; MOSCHETA, I.S.; BONATO, C.M.; BATISTA, M.A.; ALMEIDA, O.J.G. de; INOUE, T.T. (2013) Aluminum in corn plants: influence on growth and morpho-anatomy of root and leaf. Revista Brasileira de Ciência do Solo, v. 37, n. 1, p. 177-187. http://dx.doi. org/10.1590/S0100-06832013000100018

BONDY, S.C. (2016) Low levels of aluminum can lead to behavioral and morphological changes associated with Alzheimer's disease and age-related neurodegeneration. Neurotoxicology, v. 52, p. 222-229. https://doi.org/10.1016/j.neuro.2015.12.002

BRASIL. (1997) Lei no 9.433, de 8 de janeiro de 1997. Brasília.

BRASIL. (1998) Lei no 9.605, de 12 de fevereiro de 1998. Brasília.

BRASIL. (2007) Lei Federal de no 11.445, de 5 de janeiro de 2007. Diretrizes nacionais para o saneamento básico. Brasília.

CORNWELL, D.A. (2006) Water treatment residuals engineering. Denver: AWWA Research Foundation and American Water Works Association.

DILLON, G. (1996) Application Guide to Waterworks Sludge Treatment and Disposal. Blagrove: Water Research Center.

GHEYI, H.R.; PAZ, V.P.; MEDEIROS, S.S.; GALVÃO, C.O. (2012) Recursos hídricos em regiões semiáridas. Cruz das Almas: Instituto Nacional do Semiárido, Universidade Federal do Recôncavo da Bahia. 258 p.

GONÇALVES, F.; SOUZA, C.H.U.; TAHIRA, F.S.; FERNANDES, F.; TEIXEIRA, R.S. (2017) Incremento de lodo de ETA em barreiras impermeabilizantes de aterro sanitário. Revista DAE. https://doi. org/10.4322/dae.2016.018

INSTITUTO BRASILEIRO DE GEOGRAFIA E ESTATISTICA (IBGE). (2010) Pesquisa Nacional de Saneamento Básico (PNSB). Rio de Janeiro: Instituto Brasileiro de Geografia e Estatística.

INSTITUTO BRASILEIRO DE GEOGRAFIA E ESTATISTTICA (IBGE). (2014) Perfil dos Municípios Brasileiros 2013. Rio de Janeiro: Instituto Brasileiro de Geografia e Estatística. 
KATAYAMA, V.T;; MONTES, C.P.; FERRAZ, T.H.; MORITA, D.M. (2015) Quantificação da produção de lodo de estações de tratamento de água deciclo completo:umaanálise crítica. Engenharia Sanitária e Ambiental,v. 20, n. 4. http://dx.doi.org/101590/S1413-41522015020040105046

KAWAMURA, S. (1991) Integrated Design and Operation of Water Treatment Facilities. Nova York: John Wiley \& Sons. 720 p.

LATTEMANN, S.; HÖPNER, T. (2008) Environmental impact and impact assessment of seawater desalination. Desalination, v. 220, n. 1-3, p. 1-15. https://doi.org/10.1016/j.desal.2007.03.009

LIBÂNEO, M. (2010) Fundamentos de qualidade e tratamento de água. 3. ed. Campinas: Átomo. 421 p.

MERT, R.; ALAS, A.; BULUT, S.; ÖZCAN, M.M. (2014) Determination of heavy metal contents in some freshwater Fishes. Environmental Monitoring and Assessment, v. 186, n. 11, p. 8017-8022. https://doi. org/10.1007/s10661-014-3984-2

MOLINA, T. (2010) Caracterização e tratamento de água de lavagem de filtros de ETA com o uso de polímeros sintéticos e amido de batata. Revista de Engenharia e Tecnologia, v. 2, n. 3, p. 28-44.

MOREIRA, R.C.A.; BOAVENTURA, G.R.; NUNES, S.A.; PINHEIRO, L.A.; NASCIMENTO, C.T.C.; SILVA, D.R.; LIRA,C.P. (2O11) Geochemical and Geophysical Study in a Degraded Area Used for Disposal of Sludge from a Water Treatment Plant. Applied and Environmental Soil Science, v. 2011, Article ID 489182, http://dx.doi.org/10.1155/2011/489182

MOREIRA, R.C.A.; GUIMARÃES, E.M.; BOAVENTURA, G.R.A; MOMESSO, A.M.; LIMA, G.L. (2009) Estudo geoquímico da disposição de lodo de estação de tratamento de água em área degradada. Química Nova, v. 32, n. 8, p. 2085-2093. http://dx.doi. org/10.1590/S0100-40422009000800019

PADILHA, J.C. (2007) Aplicação de lodos de tratamentos de água e esgoto em latossolos cultivados com milho e soja. 345f. Dissertação (Mestrado em Ciência do Solo) - Universidade Federal do Paraná, Curitiba.

PERNAMBUCO. (1998)Secretaria de Recursos Hídricos. Plano Estadual de Recursos Hidricos e Saneamento de Pernambuco. Pernambuco: Secretaria de Recursos Hídricos. Disponível em: <http://www.srhe. pe.gov.br/index.php?option=com_content\&view=article\&id=458:perhplano-estadual-de-recursos-hidricos-1998\&catid=42:documentos\&lte mid=75>. Acesso em: 5 ago. 2014

PERNAMBUCO. (2014) Secretaria de Recursos Hídricos. Projeto de Sustentabilidade Hidrica - PSHPE, Manual de Operações. Pernambuco: Secretaria de Recursos Hídricos. v. 1. Disponível em: <http://www.sirh.srh.pe.gov.br/site/index.php?option=com content \&view=article\&id=309\&Itemid=106>. Acesso em: 15 jan. 2016.
PORTO, E.R.; AMORIM, M.C.C.; PAULINO, R.V.; MATOS, A.N.B. (2OO4) Sistema de produção usando o rejeito da dessalinização de água salobra no semi-árido Brasileiro. In: CONGRESSO BRASILEIRO DE ÁGUAS SUBTERRÂNEAS, 13., 2004. Anais... São Paulo.

REIS, E.L.T;; COTRIM, M.E.B.; RODRIGUES, C.; PIRES, M.A.F.; BELTRAME FILHO, O.; ROCHA, S.M.; CUTOLO, S.A. (2007) Identificação da influência do descarte de lodo de estações de tratamento de água. Química Nova, v. 30, n. 4, p. 865-872. http://dx.doi.org/10.1590/S010040422007000400020

RIBEIRO, F.L.M. (2007) Quantificação e caracterização química dos resíduos da ETA de Itabirito - MG. 133f. Dissertação (Mestrado) Universidade de Ouro Preto, Ouro Preto.

RITCHER, C.A. (2011) Tratamento de lodos de estações de tratamento de água. São Paulo: Edgard Blucher. 112 p.

SARON, A.; LEITE, V.M.B. (2001) Quantificação de lodo em estação de tratamento de água. In: CONGRESSO BRASILEIRO DE ENGENHARIA SANITÁRIA E AMBIENTAL, 21., 2001. Anais.. João Pessoa.

SILVA, C.A.; SILVEIRA, C.; SILVA, F.A.; KLEN, M.R.F.; BERGAMASCO, R. (2012) Classificação dos lodos formados durante o processo de coagulação/floculação da água com os coagulantes PAC e Moringa Oleifera. Engevista, v. 14, n. 3. p. 302-309. https://doi. org/10.22409/engevista.v14i3.380

TAVARES, R.G. (2003) Problemas operacionais da indústria da água: consumo excessivo de cloro na linha tronco de distribuição do sistema Gurjaú e lodos gerados pelas 6 maiores estações de tratamento de água da Região Metropolitana do Recife. 145f. Dissertação (Mestrado) - Tecnologia Ambiental e Recursos Hídricos, Departamento de Engenharia Civil, Universidade Federal de Pernambuco, Recife.

TAVARES, R.G. (2016) A atenuação do aluminio do resíduo de estações de tratamento de água por vermicompostagem e adsorção. Tese (Doutorado em Geotecnia Ambiental) - Programa de Pós-Graduação em Engenharia Civil. Universidade Federal de Pernambuco, Recife.

TAKADA, C.R.S.; SERRA, J.C.V.; MAFRA, W.A.; BORBA, K.C.A. (2013) Aproveitamento e disposição final de lodos de estações de tratamento de água no município de Palmas - TO. Engenharia Ambiental, v. 10, n. 2, p. 157-165

TSUTIYA, M.T.; HIRATA, A.Y. (2001) Aproveitamento e disposição final de lodos de Estação de Tratamento de Água do estado de São Paulo. In: CONGRESSO BRASILEIRO DE ENGENHARIA SANITÁRIA E AMBIENTAL, 2001. Anais... João Pessoa: ABES. 